\title{
Increased in the Prevalence of Plasmodium Falciparum With Kelch13 C580Y Mutations and the Decline in pfcrt and pfmdr1 Mutant Alleles in Papua New Guinea
}

\section{Naoko Yoshida}

Juntendo University: Juntendo Daigaku

Masato Yamauchi

Juntendo University

Ryosuke Morikawa

Juntendo University

Francis Hombhanje

Divine Word University

Toshihiro Mita ( $\nabla$ tmita@juntendo.ac.jp )

Juntendo university https://orcid.org/0000-0001-8180-2344

\section{Research}

Keywords: Plasmodium falciparum, Artemisinin, Chloroquine, Lumefantrine, Resistance, kelch13, pfcrt, pfmdr1, C580Y, Papua New Guinea

Posted Date: June 29th, 2021

DOl: https://doi.org/10.21203/rs.3.rs-655316/v1

License: (c) (i) This work is licensed under a Creative Commons Attribution 4.0 International License.

Read Full License 


\section{Abstract}

\section{Background}

The C580Y mutation in Plasmodium falciparum kelch13 (pfk13) is the most commonly observed variant in artemisinin-resistant isolates in the Greater Mekong Subregion (GMS). Until 2017, it had not been identified outside GMS, except for Guyana. In 2017, we identified three parasites carrying the C580Y mutation in Papua New Guinea (PNG). As the C580Y allele rapidly spread in the GMS, there is concern that this mutant is now spreading in PNG.

\section{Methods}

In 2020, we conducted a cross-sectional survey at two clinics in Wewak, PNG. Symptomatic patients infected with $P$. falciparum were treated with artemether plus lumefantrine following a national treatment policy. Blood samples were obtained before treatment, and polymorphisms in pfk 13 , pfcrt, and pfmdr1 were determined. Parasite positivity was examined on day 3.

\section{Results}

A total of 94 patients were included in this analysis. The prevalence of C580Y was significantly increased (2.2\% in 2017, $5.7 \%$ in 2018, and $6.4 \%$ in $\left.2020 ; p=4.2 \times 10^{-3}\right)$. A significant upward trend of wild-type prevalence was found for $p f c r t\left(1.9 \%\right.$ in 2016 to $46.7 \%$ in $\left.2020 ; p=8.9 \times 10^{-16}\right)$ and $p f m d r 1$ ( $59.5 \%$ in 2016 to $91.4 \%$ in $\left.2020 ; p=2.3 \times 10^{-6}\right)$. Among 26 patients, including three with C580Y infections successfully followed on day 3 , none showed positive parasitemia.

\section{Conclusions}

Under the conditions of significant increases in pfcrt K76 and pfmdr1 N86 alleles in PNG, the increase in pfk13 C580Y mutants may be a warning indicator of the emergence of parasites resistant to the currently used first-line treatment regimen of artemether plus lumefantrine. Therefore, nationwide surveillance of molecular markers for drug resistance and assessment of its therapeutic effect, are important.

\section{Background}

Artemisinin (ART)-based combination therapy (ACT) is a widely used first-line treatment for uncomplicated malaria. Malaria deaths have markedly decreased since the introduction of the treatment in the early 2000s [1]. However, the emergence of ART-resistant $P$. falciparum was first reported in the Greater Mekong Subregion (GMS) in 2006 [2-4]. Since then, ART-resistant parasites have rapidly spread in the region, partly because of the emergence of resistance to partner drug(s) of ACT $[5,6]$. Therefore, the emergence and spread of RT-resistant parasites outside the GMS has become a global concern.

Propeller polymorphisms of the $p f k 13$ gene are useful molecular markers to monitor the emergence and spread of ART resistance [4, 7]. To date, ten or more non-synonymous mutations in $p f k 13$ have been 
validated as polymorphisms for ART resistance. These include N458Y, Y493H, R539T, I543T, R561H, and C580Y [8]. In particular, C580Y has gradually outcompeted the other mutations and become dominant in some parts of the GMR region (GMSR) $[5,9,10]$. C580Y is considered the most useful molecular marker to trace the spread of ART resistance in GMS. However, outside the GMSR, this mutation has been detected only in Guyana $[11,12]$ and, as we reported more recently, in Papua New Guinea (PNG) [13].

In PNG, chloroquine plus sulfadoxine/pyrimethamine had been adopted as the official first-line treatment regimen for uncomplicated malaria by 2010 . This therapy was subsequently replaced with artemether plus lumefantrine (AL). In 2017, we identified three $P$. falciparum parasites harboring C580Y in Wewak, East Sepik. Population-genetic analysis using whole-genome and haplotypes of $p f k 13$ flanking microsatellite markers suggested that the C580Y in PNG did not migrate from Southeast Asia. Rather, it had independently emerged from another region in New Guinea [13]. Considering the aggressive increase in the C580Y harboring parasites in GMSR, there is a growing concern that a similar phenomenon may occur in PNG. Therefore, it is essential to assess whether parasites harboring C580Y have increased in the parasite population in PNG.

In addition to the issue of ART resistance, our previous ex vivo drug study also found that most $P$. falciparum parasites were resistant to chloroquine despite the discontinuation of chloroquine use in the early 2010s [14]. This is contrary to the observations in many African countries where chloroquine susceptibility recovered years after discontinuation [15-28].

To evaluate whether levels of ART-resistant molecular markers have increased since the first emergence and whether chloroquine resistance persists, a molecular epidemiological study was performed in 2020 in Wewak, East Sepik. Ex vivo drug susceptibility studies had previously been conducted there in 2002, 2003 , and 2016-2018 [13, 14, 29-31]. The results we describe show a significant increase in C580Y prevalence and the potential recovery of chloroquine susceptibility.

\section{Methods}

\section{Study design and site}

This study was conducted at two clinics (Wirui Urban and Town) in January and February 2020 in Wewak District, East Sepik Province, PNG [14]. The study area comprises a lowland swamp along the coast. High transmission rates of malaria occur throughout the year, with seasonal fluctuations [32]. All four Plasmodium species for human malaria were observed in this region, with $P$. falciparum predominant.

Ethical approval for the study was obtained from the Medical Research Ethical Committee of Juntendo University (No. 2017070) and the Medical Research Advisory Committee of the PNG National Department of Health (MRAC No.16.41).

\section{Patients and blood collection}


In both clinics, patients with suspected malarial symptoms were screened using the Rapid Diagnosis Test (RDT) (Carestart ${ }^{\text {TM }}$ Malaria HRP2/pLDH COMBO, Access Bio Inc., NJ, USA). Patients $>1$ year of age with Plasmodium-positive results were recruited for the study and were enrolled after obtaining informed consent from the patients or their guardians. Blood samples $(100 \mu \mathrm{l})$ were obtained by finger prick and transferred onto ET31CHR chromatography filter paper (Whatman Limited, Kent, UK). After drying at room temperature, the samples were separated in a plastic bag and stored at $-20^{\circ} \mathrm{C}$. Thick and thin blood smears were prepared and stained with $2 \%$ Giemsa for 45 min for parasite counting. All $P$. falciparum positive patients were treated with the AL regimen according to national guidelines and were asked to visit the clinics to evaluate parasite positivity on day 3 of treatment.

\section{Malaria PCR, genotyping of pfk13, pfcrt, and pfmdr1}

Parasite DNA was extracted from one-quarter of each blood spot using the QIAamp DNA Blood Mini Kit (QIAGEN, Hilden, Germany). P. falciparum positivity was confirmed by species-specific PCR as previously described [33]. Polymorphisms were determined by direct sequencing, as previously described [14] and included the $p f k 13$ gene (propeller domain amino acid positions 427-726), P. falciparum chloroquine resistance transporter gene ( $p f c r t$, amino acid positions $72-76$ ), and $P$. falciparum multidrug resistance-1 gene (pfmdr1; amino acid positions $86,184,1034,1042$, and 1246). Allele prevalence of $p f k 13$, pfcrt, and pfmdr1 in 2020 were compared to those in 2002, 2003, and 2016-2018 [13, 14, 29]. The genotypes of pfk13 in 2018 were analyzed using the same samples previously reported [14].

\section{Statistical analysis}

Statistical analysis was performed using R software (version 4.1.0), with the Chi-square test for trend (Cochran-Armitage trend test). Statistical significance was set at $p<0.05$.

\section{Results}

\section{Patients and Plasmodium sp. specific PCR}

Among the 335 patients screened with RDT, 118 had positive results for Plasmodium (Fig. 1). Of these, species-specific PCR revealed that 13 were parasite negative and nine were other species, resulting in 96 patients with $P$. falciparum (Additional file 1). Two patients who received an intramuscular injection of artemether within two weeks prior to enrollment were excluded from further analysis. Finally, 94 samples were used for molecular analysis. There were no significant differences in the background characteristics of the enrolled patients between the two clinics (Table 1). The median age was 17 years and the median parasitemia was $0.74 \%$. No significant difference was observed between patient number, age, sex, and average parasitemia in each year (Additional file 2). 
Table 1

Characteristics of studied patients

\begin{tabular}{|c|c|c|}
\hline Characteristic & $\begin{array}{l}\text { Day } 1 \\
(n=94)\end{array}$ & $\begin{array}{l}\text { Day } 3 \\
(n=27)\end{array}$ \\
\hline \multicolumn{3}{|l|}{ Sampling clinics; $\mathrm{n}$} \\
\hline Wirui & 46 & 7 \\
\hline Town & 48 & 20 \\
\hline \multicolumn{3}{|l|}{ Age; $n$} \\
\hline $0-9$ & 10 & 4 \\
\hline $10-19$ & 41 & 7 \\
\hline $20-$ & 43 & 16 \\
\hline Median (IQR) & $17(13,26.5)$ & $25(14.5,33)$ \\
\hline \multicolumn{3}{|l|}{ Sex; n } \\
\hline Male & 47 & 12 \\
\hline Female & 47 & 15 \\
\hline \multicolumn{3}{|l|}{ Symptoms; n (\%) } \\
\hline Muscle or joint aches & $24(26)$ & $4(15)$ \\
\hline Chill/Shivering & $36(38)$ & $4(15)$ \\
\hline Headache & $60(64)$ & $9(33)$ \\
\hline Nausea/Vomiting & $18(19)$ & $1(4)$ \\
\hline Abdominal pain & $14(15)$ & 0 \\
\hline Diarrhea & $7(7)$ & $2(7)$ \\
\hline Cough & $24(26)$ & $3(11)$ \\
\hline Convulsions & $8(9)$ & $1(4)$ \\
\hline Temperature $\left(>37.5^{\circ} \mathrm{C}\right)$ & $47(50)$ & $2(7)$ \\
\hline Parasitemia*, & 0.74 & 0 \\
\hline $\begin{array}{l}\text { Median (\%) } \\
(\text { IQR) }\end{array}$ & $(0.35,1.5)$ & \\
\hline
\end{tabular}


C580Y was the only mutation observed in pfk 13 and was identified in six patients (5.2\%) in 2018 and six $(6.4 \%)$ in 2020 (Fig. 2). Since the first detection of C580Y in three patients (2.2\%) in 2017 [13], there has been a statistically significant increase in the prevalence of C580Y $\left(p=4.2 \times 10^{-3}\right.$, Cochran-Armitage trend test).

In both pfcrt and pfmdr1, the majority of parasites harbored chloroquine resistant types in 2002 and 2003 [29]. However, a marked shift of allele prevalence to chloroquine-sensitive types was observed after the mid-2010s (Fig. 2). In pfcrt, there were two haplotypes: wild-type (CVMNK) and mutant (SVMNT; mutation underlined). Wild-type prevalence significantly increased from $1.9 \%$ in 2016 to $46.7 \%$ in 2020 ( $p=8.9 \times 10^{-}$ 16, Cochran-Armitage trend test). In pfmdr1, the N86 allele also significantly increased from $59.5 \%$ in 2016 to $91.4 \%$ in 2020 ( $p=2.3 \times 10^{-6}$, Cochran-Armitage trend test). The transition to the chloroquine-sensitive form of $p f m d r 1$ occurred at least three years earlier than that of $p f c r t$. In fact, the prevalence of the pfmdr1 N86 allele in 2016 was higher than that of $\mathrm{K} 76$ in pfcrt in 2020. Although polymorphisms were observed at positions 184 and 1042, the prevalence fluctuated annually without any upward or downward trends. Only the wild-type allele was found throughout the study period at positions 1034 and 1246.

\section{Follow-up of patients on day 3}

Among the 94 patients treated with AL, 27 were successfully followed-up with clinical assessment on day 3. The patients included three infected with the C580Y mutant. Only one patient was afebrile on day 3. Prevalent symptoms remaining on day 3 were headache (33\%) and muscle/joint pain (15\%). All follow-up patients showed an absence of parasites on day 3 smears. There were no cases of early treatment failure.

\section{Discussion}

We commenced an epidemiological study related to malaria drug resistance in 2002 in East Sepik, PNG $[29,30]$. After a long interval from 2004 to 2015, the study was restarted in 2016 [14]. In 2017, we identified three $p f k 13 \mathrm{C} 580 \mathrm{Y}$ mutants [13]. This raised concern that ART-resistant $P$. falciparum parasites may have already emerged and spread in the study area. In this study, the prevalence of $p f k 13 \mathrm{C} 580 \mathrm{Y}$ was relatively low, but it had increased significantly since the first detection. In general, drug-resistant malaria increases slowly at the beginning of an emergence, but increases rapidly as the frequency of resistant parasites increases. Indeed, C580Y frequencies gradually increased approximately five years from the initial detection, but then rapidly expanded and even overtook the other $p f k 13$ alleles in Cambodia and Western Thailand $[5,9,10]$. Therefore, even though the current prevalence of $p f k 13 \mathrm{C} 580 \mathrm{Y}$ is low in PNG, rapid expansion in the near future could be anticipated.

On the other hand, regional malaria epidemiological factors in PNG may suppress the rapid increase in ART-resistant parasites. First, residents in our study area developed higher levels of herd immunity to malaria than those in the GMSR because of higher malaria transmission intensity in PNG [34,35]. This 
can considerably influence the clearance of ART-resistant parasites from human hosts [36] and may slow the rate of increase in the C580Y allele in the region. Second, because ART is primarily used in ACT, the presence of resistant parasites to ACT partner drugs significant affects the diffusion rate of C580Y. In the GMSR, parasites resistant to partner drug(s), mefloquine, and piperaquine have already emerged and spread $[37,38]$. In particular, parasites harboring both pfk 13 C580Y and plasmepsin $2 / 3$ copy number variants, which are molecular markers for piperaquine resistance, have rapidly increased in West Cambodia [5, 39]. In contrast, in PNG there is no evidence that parasites are resistant to lumefantrine, the currently used partner drug of ACT. Our previous ex vivo drug susceptibility study from 2016 to 2018 also demonstrated that the average $\mathrm{IC}_{50}$ to lumefantrine was $4.6 \mathrm{nM}$ and no parasite fulfilled the criteria of ex vivo lumefantrine resistance [14]. Furthermore, we found that no patient exhibited parasite positivity on day 3 , although the follow-up number was small.

The effects of the C580Y mutation on ART resistance are important determinants of the survival of drugresistant parasites. However, the introduction of $\mathrm{C} 580 \mathrm{Y}$ into $P$. falciparum clones did not substantially increase the level of in vitro ART resistance compared to other mutations, such as R539T [40]. In addition, drug-resistant mutations generally confer a decrease in parasite fitness, which often leads to a survival disadvantage [41-44]. Several laboratory studies have demonstrated that the growth rates of C580Y harboring transgenic parasites were equal to or less than those of transgenic parasites with other $p f k 13$ mutations, such as R561H, E252Q, and G538V, suggesting that C580Y incurs at least a similar level of fitness impairment to the other pfk 13 mutations $[40,45,46]$. These laboratory findings are inconsistent with the field observations in the GMSR where the C580Y mutant has outcompeted other mutants [5, 9, 10]. This implies that some unique background genetic changes in the South-East Asia (SEA) parasites play a beneficial role in the survival of the SEA parasites harboring the C580Y allele. This might include compensation for the harmful effects of the C580Y mutation. Several single nucleotide polymorphisms (SNPs) have been identified in SEA pfk13 isolates [47]. However, among these SNPs, only one (ferredoxin D193Y) was found in our PNG C580Y mutants [13], suggesting that PNG C580Y mutants do not possess the same background genetic changes as SEA C580Y mutants.

As for chloroquine susceptibility, we previously reported that the average $\mathrm{IC}_{50 \text { s }}$ values were still high (80.5-106.6 nM) with a low prevalence of pfcrt K76 wild-type (2.3-11.7\%) during 2016-2018 [14]. In 2020 , however, the prevalence of pfcrt K76 wild-type rapidly increased to $46.7 \%$. Since a significant association between the pfcrt $\mathrm{K} 76$ wild-type allele and ex vivo chloroquine susceptibility was confirmed in our study area [14], the observed rapid increase in the pfcrt K76 allele suggests that chloroquine sensitivity has been recovering. The significant increase in pfmdr1 N86 wild-type from $59.5-91.4 \%$ in the three years to 2020 also suggests the potential resurgence of chloroquine sensitivity. Although this phenomenon has been widely observed in African countries [15-26, 28], it is very rare in SEA [48].

We previously found that decreased ex vivo susceptibility to lumefantrine was significantly associated with pfmdr1 N86 [14], consistent with a previous transfection study showing that an allelic change from $\mathrm{N} 86 \mathrm{Y}$ to N86 increased $\mathrm{IC}_{50}$ for lumefantrine three to four times [49]. Thereare considerable reports that pfmdr1 N86 wild-type is selected by AL treatment $[50,51]$. Furthermore, a recent meta-analysis of $60 \mathrm{AL}$ 
clinical trials revealed that only $38 \%$ of patients treated with $\mathrm{AL}$ were symptomatic when the infection recurred [52]. If patients are asymptomatic at the time of recurrence, they are unlikely to seek treatment, resulting in the persistence of parasitemia. This would increase the chance that the parasites could be transmitted to other human hosts, which could subsequently spread the drug-resistant mutations in the parasite population. In addition, a specific pfmdr1 haplotype (multicopy pfmdr1 in addition to N86 and $\mathrm{Y} 184 \mathrm{~F}$ ) has increased and become predominant in Cambodia and Vietnam [53]. Gene editing experiments showed that this haplotype significantly reduces parasite susceptibility to lumefantrine [53]. In our study site, although this haplotype was not detected [13], all these genetic changes (multicopy pfmdr1, N86, and Y184F) were individually observed. Therefore, in addition to the assessment of the relapse rate following $\mathrm{AL}$, it is necessary to monitor the appearance of this haplotype.

\section{Conclusions}

Since its first identification in 2017, pfk 13 C580Y harboring $P$. falciparum parasites have been increasing in Wewak, East Sepik, PNG. A significant increase in pfcrt K76 and pfmdr1 N86 was also observed. This suggests a possible recovery of chloroquine sensitivity and, on the other hand, a decrease in sensitivity to lumefantrine, the ACT partner drug. The increasing frequency of pfk $13 \mathrm{C} 580 \mathrm{Y}$ mutants under these circumstances is a warning sign that parasites resistant to AL will emerge in the near future. Thus, it is important to enhance continuous monitoring to detect early signs of the emergence of ACT-resistant parasites.

\section{Abbreviations}

ACT: artemisinin combination therapy

ART: artemisinin

$\mathrm{AL}:$ artemether plus lumefantrine

GMS: Greater Mekong Subregion

$\mathrm{IC}_{50}: 50 \%$ growth inhibitory concentration

IQR: Inter Quartile Range

kelch13: pfk13

PCR: polymerase chain reaction

PNG: Papua New Guinea

RDT: rapid diagnostic test

SEA: Southeast Asia 
SNP: Single nucleotide polymorphism

\section{Declarations}

\section{Ethics approval and consent to participate}

Ethical approval was obtained from the Medical Research Ethical Committee of Juntendo University (No. 2017070) and the Medical Research Advisory Committee of the Papua New Guinea National Department of Health (MRAC No. 16.41).

\section{Consent for publication}

Prior to participation, all study subjects consented to the publication of study results in the medical literature in an anonymized manner.

\section{Availability of data and materials}

The primary datasets used and analyzed during the current study are available from the corresponding author upon reasonable request.

\section{Competing interests}

All authors declare no competing interests.

\section{Funding}

This study was financially supported by Grants-in-aid for scientific research [26305015, 17H04074,18KK0231] from Ministry of Education, Culture, Sports, Science and Technology (MEXT) of Japan awarded to Professor Toshihiro Mita.

\section{Authors' contributions}

NY and TM designed and coordinated the study; MY, ST, and FH performed the field study; NY and RM performed the laboratory work; NY and TM analyzed and interpreted the data; NY and TM wrote the manuscript. All the authors contributed significantly to this work. All authors read and approved the final manuscript.

\section{Acknowledgments}

We thank all the study participants and their guardians. We are grateful to Steven Tiwara, Charlie Amai, Alphonse Coll, John Sambi and Douglas Tambi, and staff from Wewak Clinic, Town Clinic, for their kind cooperation in the field. We also thank Shuxin Song for technical assistance.

\section{References}


1. Murray CJ, Rosenfeld LC, Lim SS, Andrews KG, Foreman KJ, Haring D, Fullman N, Naghavi M, Lozano R, Lopez AD: Global malaria mortality between 1980 and 2010: a systematic analysis. Lancet 2012, 379:413-431.

2. Noedl H, Se Y, Schaecher K, Smith BL, Socheat D, Fukuda MM: Evidence of artemisinin-resistant malaria in western Cambodia. N Engl J Med 2008, 359:2619-2620.

3. Dondorp AM, Nosten F, Yi P, Das D, Phyo AP, Tarning J, Lwin KM, Ariey F, Hanpithakpong W, Lee SJ, et al: Artemisinin resistance in Plasmodium falciparum malaria. N Engl J Med 2009, 361:455-467.

4. Ashley EA, Dhorda M, Fairhurst RM, Amaratunga C, Lim P, Suon S, Sreng S, Anderson JM, Mao S, Sam B, et al: Spread of artemisinin resistance in Plasmodium falciparum malaria. $N$ Engl J Med 2014, 371:411-423.

5. Imwong M, Dhorda M, Myo Tun K, Thu AM, Phyo AP, Proux S, Suwannasin K, Kunasol C, Srisutham S, Duanguppama J, et al: Molecular epidemiology of resistance to antimalarial drugs in the Greater Mekong subregion: an observational study. Lancet Infect Dis 2020, 20:1470-1480.

6. Imwong M, Suwannasin K, Kunasol C, Sutawong K, Mayxay M, Rekol H, Smithuis FM, Hlaing TM, Tun KM, van der Pluijm RW, et al: The spread of artemisinin-resistant Plasmodium falciparum in the Greater Mekong subregion: a molecular epidemiology observational study. Lancet Infect Dis 2017, 17:491-497.

7. Ariey F, Witkowski B, Amaratunga C, Beghain J, Langlois AC, Khim N, Kim S, Duru V, Bouchier C, Ma L, et al: A molecular marker of artemisinin-resistant Plasmodium falciparum malaria. Nature 2014, 505:50-55.

8. WHO: World Malaria Report 2020. 2020.

9. Anderson TJ, Nair S, McDew-White M, Cheeseman IH, Nkhoma S, Bilgic F, McGready R, Ashley E, Pyae Phyo A, White NJ, Nosten F: Population Parameters Underlying an Ongoing Soft Sweep in Southeast Asian Malaria Parasites. Mol Biol Evol 2017, 34:131-144.

10. Imwong M, Hien TT, Thuy-Nhien NT, Dondorp AM, White NJ: Spread of a single multidrug resistant malaria parasite lineage (PfPailin) to Vietnam. Lancet Infect Dis 2017, 17:1022-1023.

11. Chenet SM, Akinyi Okoth S, Huber CS, Chandrabose J, Lucchi NW, Talundzic E, Krishnalall K, Ceron N, Musset L, Macedo de Oliveira A, et al: Independent Emergence of the Plasmodium falciparum Kelch Propeller Domain Mutant Allele C580Y in Guyana. J Infect Dis 2016, 213:1472-1475.

12. Mathieu LC, Cox H, Early AM, Mok S, Lazrek Y, Paquet JC, Ade MP, Lucchi NW, Grant Q, Udhayakumar $\mathrm{V}$, et al: Local emergence in Amazonia of Plasmodium falciparum k13 C580Y mutants associated with in vitro artemisinin resistance. Elife 2020, 9: e51015.

13. Miotto O, Sekihara M, Tachibana SI, Yamauchi M, Pearson RD, Amato R, Gonçalves S, Mehra S, Noviyanti R, Marfurt J, et al: Emergence of artemisinin-resistant Plasmodium falciparum with kelch13 C580Y mutations on the island of New Guinea. PLoS Pathog 2020, 16:e1009133.

14. Sekihara M, Tachibana SI, Yamauchi M, Yatsushiro S, Tiwara S, Fukuda N, Ikeda M, Mori T, Hirai M, Hombhanje F, Mita T: Lack of significant recovery of chloroquine sensitivity in Plasmodium 
falciparum parasites following discontinuance of chloroquine use in Papua New Guinea. Malar $J$ 2018, 17:434.

15. Mita T, Kaneko A, Lum JK, Bwijo B, Takechi M, Zungu IL, Tsukahara T, Tanabe K, Kobayakawa T, Björkman A: Recovery of chloroquine sensitivity and low prevalence of the Plasmodium falciparum chloroquine resistance transporter gene mutation K76T following the discontinuance of chloroquine use in Malawi. Am J Trop Med Hyg 2003, 68:413-415.

16. Laufer MK, Thesing PC, Eddington ND, Masonga R, Dzinjalamala FK, Takala SL, Taylor TE, Plowe CV: Return of chloroquine antimalarial efficacy in Malawi. N Engl J Med 2006, 355:1959-1966.

17. Akala HM, Eyase FL, Cheruiyot AC, Omondi AA, Ogutu BR, Waters NC, Johnson JD, Polhemus ME, Schnabel DC, Walsh DS: Antimalarial drug sensitivity profile of western Kenya Plasmodium falciparum field isolates determined by a SYBR Green I in vitro assay and molecular analysis. Am J Trop Med Hyg 2011, 85:34-41.

18. Eyase FL, Akala HM, Ingasia L, Cheruiyot A, Omondi A, Okudo C, Juma D, Yeda R, Andagalu B, Wanja $\mathrm{E}$, et al: The role of Pfmdr1 and Pfcrt in changing chloroquine, amodiaquine, mefloquine and lumefantrine susceptibility in western-Kenya P. falciparum samples during 2008-2011. PLOS One 2013, 8:e64299.

19. Fall B, Pascual A, Sarr FD, Wurtz N, Richard V, Baret E, Diémé Y, Briolant S, Bercion R, Wade B, et al: Plasmodium falciparum susceptibility to anti-malarial drugs in Dakar, Senegal, in 2010: an ex vivo and drug resistance molecular markers study. Malar J 2013, 12:107.

20. Issaka M, Salissou A, Arzika I, Guillebaud J, Maazou A, Specht S, Zamanka H, Fandeur T: Ex vivo responses of Plasmodium falciparum clinical isolates to conventional and new antimalarial drugs in Niger. Antimicrob Agents Chemother 2013, 57:3415-3419.

21. Mohammed A, Ndaro A, Kalinga A, Manjurano A, Mosha JF, Mosha DF, van Zwetselaar M, Koenderink JB, Mosha FW, Alifrangis M, et al: Trends in chloroquine resistance marker, Pfcrt-K76T mutation ten years after chloroquine withdrawal in Tanzania. Malar J 2013, 12:415.

22. Quashie NB, Duah NO, Abuaku B, Quaye L, Ayanful-Torgby R, Akwoviah GA, Kweku M, Johnson JD, Lucchi NW, Udhayakumar V, et al: A SYBR Green 1-based in vitro test of susceptibility of Ghanaian Plasmodium falciparum clinical isolates to a panel of anti-malarial drugs. Malar J 2013, 12:450.

23. Frosch AE, Laufer MK, Mathanga DP, Takala-Harrison S, Skarbinski J, Claassen CW, Dzinjalamala FK, Plowe CV: Return of widespread chloroquine-sensitive Plasmodium falciparum to Malawi. $J$ Infect Dis 2014, 210:1110-1114.

24. Tinto H, Bonkian LN, Nana LA, Yerbanga I, Lingani M, Kazienga A, Valéa I, Sorgho H, Kpoda H, Guiguemdé TR, et al: Ex vivo anti-malarial drugs sensitivity profile of Plasmodium falciparum field isolates from Burkina Faso five years after the national policy change. Malar J 2014, 13:207.

25. Mbaye A, Gaye A, Dieye B, Ndiaye YD, Bei AK, Affara M, Deme AB, Yade MS, Diongue K, Ndiaye IM, et al: Ex vivo susceptibility and genotyping of Plasmodium falciparum isolates from Pikine, Senegal. Malar J 2017, 16:250. 
26. Lucchi NW, Komino F, Okoth SA, Goldman I, Onyona P, Wiegand RE, Juma E, Shi YP, Barnwell JW, Udhayakumar V, Kariuki S: In Vitro and Molecular Surveillance for Antimalarial Drug Resistance in Plasmodium falciparum Parasites in Western Kenya Reveals Sustained Artemisinin Sensitivity and Increased Chloroquine Sensitivity. Antimicrob Agents Chemother 2015, 59:7540-7547.

27. Mita T, Kaneko A, Lum JK, Zungu IL, Tsukahara T, Eto H, Kobayakawa T, Björkman A, Tanabe K: Expansion of wild type allele rather than back mutation in pfcrt explains the recent recovery of chloroquine sensitivity of Plasmodium falciparum in Malawi. Mol Biochem Parasitol 2004, 135:159163.

28. Balikagala B, Sakurai-Yatsushiro M, Tachibana SI, Ikeda M, Yamauchi M, Katuro OT, Ntege EH, Sekihara M, Fukuda N, Takahashi N, et al: Recovery and stable persistence of chloroquine sensitivity in Plasmodium falciparum parasites after its discontinued use in Northern Uganda. Malar J 2020, 19:76.

29. Mita T, Kaneko A, Hombhanje F, Hwaihwanje I, Takahashi N, Osawa H, Tsukahara T, Masta A, Lum JK, Kobayakawa T, et al: Role of pfmdr1 mutations on chloroquine resistance in Plasmodium falciparum isolates with pfcrt K76T from Papua New Guinea. Acta Trop 2006, 98:137-144.

30. Mita T, Kaneko A, Hwaihwanje I, Tsukahara T, Takahashi N, Osawa H, Tanabe K, Kobayakawa T, Björkman A: Rapid selection of dhfr mutant allele in Plasmodium falciparum isolates after the introduction of sulfadoxine/pyrimethamine in combination with 4-aminoquinolines in Papua New Guinea. Infect Genet Evol 2006, 6:447-452.

31. Mita T, Hombhanje F, Takahashi N, Sekihara M, Yamauchi M, Tsukahara T, Kaneko A, Endo H, Ohashi $\mathrm{J}$ : Rapid selection of sulphadoxine-resistant Plasmodium falciparum and its effect on withinpopulation genetic diversity in Papua New Guinea. Sci Rep 2018, 8:5565.

32. Muller I, Bockarie M, Alpers M, Smith T: The epidemiology of malaria in Papua New Guinea. Trends Parasitol 2003, 19:253-259.

33. Rubio JM, Benito A, Berzosa PJ, Roche J, Puente S, Subirats M, Lopez-Velez R, Garcia L, Alvar J: Usefulness of seminested multiplex PCR in surveillance of imported malaria in Spain. J Clin Microbiol 1999, 37:3260-3264.

34. Rogerson SJ, Wijesinghe RS, Meshnick SR: Host immunity as a determinant of treatment outcome in Plasmodium falciparum malaria. Lancet Infect Dis 2010, 10:51-59.

35. Kattenberg JH, Gumal DL, Ome-Kaius M, Kiniboro B, Philip M, Jally S, Kasian B, Sambale N, Siba PM, Karl S, et al: The epidemiology of Plasmodium falciparum and Plasmodium vivax in East Sepik Province, Papua New Guinea, pre- and post-implementation of national malaria control efforts. Malar J 2020, 19:198.

36. Ataide R, Ashley EA, Powell R, Chan JA, Malloy MJ, O'Flaherty K, Takashima E, Langer C, Tsuboi T, Dondorp AM, et al: Host immunity to Plasmodium falciparum and the assessment of emerging artemisinin resistance in a multinational cohort. Proc Natl Acad Sci U S A 2017, 114:3515-3520.

37. Spring MD, Lin JT, Manning JE, Vanachayangkul P, Somethy S, Bun R, Se Y, Chann S, Ittiverakul M, Sia-ngam $\mathrm{P}$, et al: Dihydroartemisinin-piperaquine failure associated with a triple mutant including 
kelch13 C580Y in Cambodia: an observational cohort study. Lancet Infect Dis 2015, 15:683-691.

38. van der Pluijm RW, Imwong M, Chau NH, Hoa NT, Thuy-Nhien NT, Thanh NV, Jittamala P, Hanboonkunupakarn B, Chutasmit K, Saelow C, et al: Determinants of dihydroartemisininpiperaquine treatment failure in Plasmodium falciparum malaria in Cambodia, Thailand, and Vietnam: a prospective clinical, pharmacological, and genetic study. Lancet Infect Dis 2019, 19:952961.

39. Amato R, Lim P, Miotto O, Amaratunga C, Dek D, Pearson RD, Almagro-Garcia J, Neal AT, Sreng S, Suon S, et al: Genetic markers associated with dihydroartemisinin-piperaquine failure in Plasmodium falciparum malaria in Cambodia: a genotype-phenotype association study. Lancet Infect Dis 2017, 17:164-173.

40. Nair S, Li X, Arya GA, McDew-White M, Ferrari M, Nosten F, Anderson TJC: Fitness Costs and the Rapid Spread of kelch13-C580Y Substitutions Conferring Artemisinin Resistance. Antimicrob Agents Chemother 2018, 62.

41. Mackinnon MJ, Hastings IM: The evolution of multiple drug resistance in malaria parasites. Trans $R$ Soc Trop Med Hyg 1998, 92:188-195.

42. Hastings IM, Donnelly MJ: The impact of antimalarial drug resistance mutations on parasite fitness, and its implications for the evolution of resistance. Drug Resist Updat 2005, 8:43-50.

43. Walliker D, Hunt P, Babiker H: Fitness of drug-resistant malaria parasites. Acta Trop 2005, 94:251-259.

44. Rosenthal PJ: The interplay between drug resistance and fitness in malaria parasites. Mol Microbiol 2013, 89:1025-1038.

45. Straimer J, Gnadig NF, Stokes BH, Ehrenberger M, Crane AA, Fidock DA: Plasmodium falciparum K13 Mutations Differentially Impact Ozonide Susceptibility and Parasite Fitness In Vitro. mBio $2017,8$.

46. Tirrell AR, Vendrely KM, Checkley LA, Davis SZ, McDew-White M, Cheeseman IH, Vaughan AM, Nosten FH, Anderson TJC, Ferdig MT: Pairwise growth competitions identify relative fitness relationships among artemisinin resistant Plasmodium falciparum field isolates. Malar J 2019, 18:295.

47. Miotto O, Amato R, Ashley EA, Maclnnis B, Almagro-Garcia J, Amaratunga C, Lim P, Mead D, Oyola SO, Dhorda M, et al: Genetic architecture of artemisinin-resistant Plasmodium falciparum. Nat Genet 2015, 47:226-234.

48. Liu DQ, Liu RJ, Ren DX, Gao DQ, Zhang CY, Qui CP, Cai XZ, Ling CF, Song AH, Tang X: Changes in the resistance of Plasmodium falciparum to chloroquine in Hainan, China. Bull World Health Organ 1995, 73:483-486.

49. Veiga MI, Dhingra SK, Henrich PP, Straimer J, Gnädig N, Uhlemann AC, Martin RE, Lehane AM, Fidock DA: Globally prevalent PfMDR1 mutations modulate Plasmodium falciparum susceptibility to artemisinin-based combination therapies. Nat Commun 2016, 7:11553.

50. Sisowath C, Strömberg J, Mårtensson A, Msellem M, Obondo C, Björkman A, Gil JP: In vivo selection of Plasmodium falciparum pfmdr1 $86 \mathrm{~N}$ coding alleles by artemether-lumefantrine (Coartem). J Infect Dis 2005, 191:1014-1017. 
51. Sisowath C, Petersen I, Veiga MI, Mårtensson A, Premji Z, Björkman A, Fidock DA, Gil JP: In vivo selection of Plasmodium falciparum parasites carrying the chloroquine-susceptible pfcrt K76 allele after treatment with artemether-lumefantrine in Africa. J Infect Dis 2009, 199:750-757.

52. Mumtaz R, Okell LC, Challenger JD: Asymptomatic recrudescence after artemether-lumefantrine treatment for uncomplicated falciparum malaria: a systematic review and meta-analysis. Malar J 2020, 19:453.

53. Calçada C, Silva M, Baptista V, Thathy V, Silva-Pedrosa R, Granja D, Ferreira PE, Gil JP, Fidock DA, Veiga MI: Expansion of a Specific Plasmodium falciparum PfMDR1 Haplotype in Southeast Asia with Increased Substrate Transport. mBio 2020, 11: e02093-20.

\section{Figures}

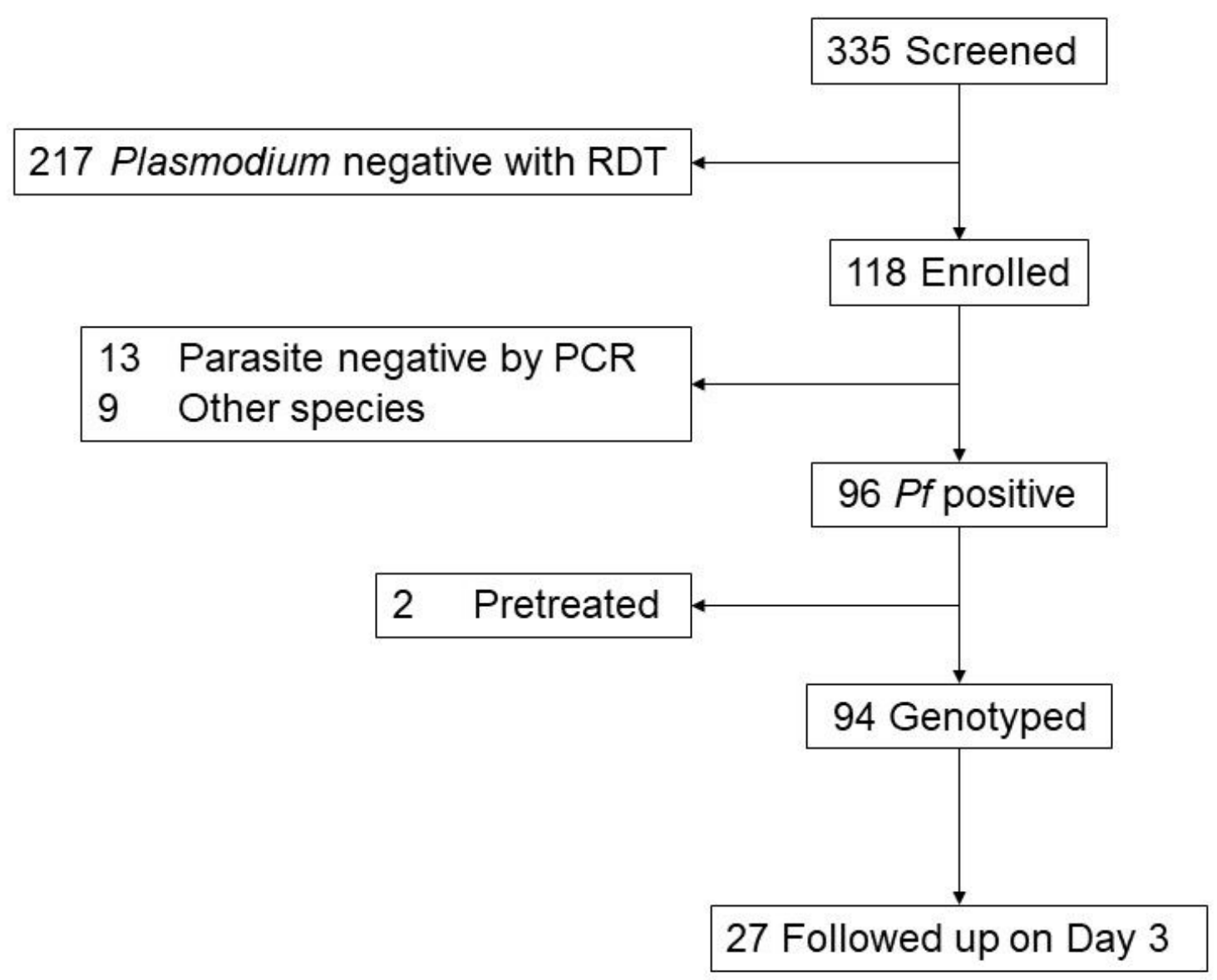

Figure 1

Flow chart of the study 


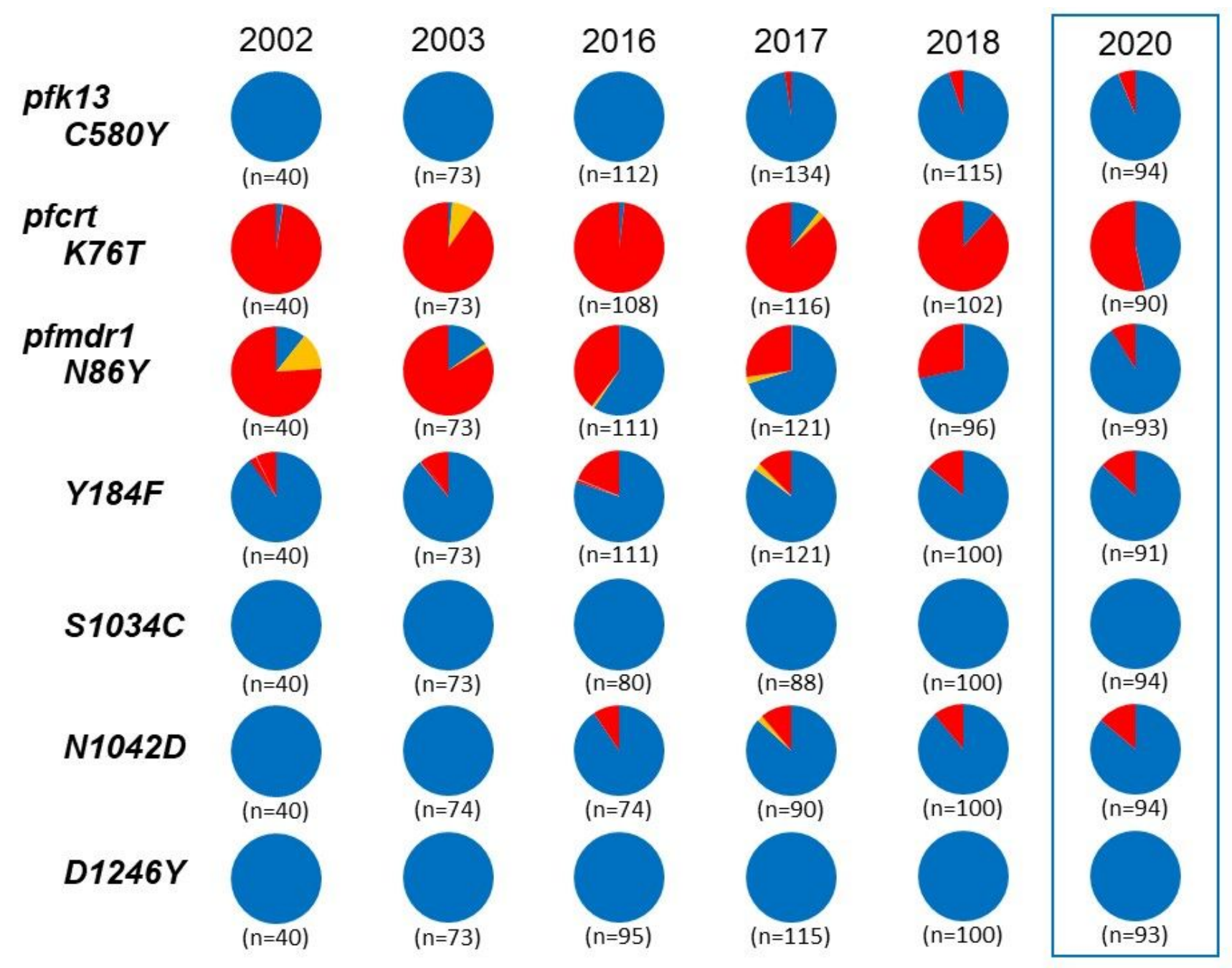

Figure 2

Temporal changes in pfk13, pfcrt and pfmdr1 allele prevalence in 2002, 2003, and 2016-2020. The allele type corresponding to each color is blue for the wild-type, yellow for the mix, and red for the mutant.

\section{Supplementary Files}

This is a list of supplementary files associated with this preprint. Click to download.

- AdditionalFile1.docx

- AdditionalFile2.docx 